\title{
Congenital hypothyroidism with delayed TSH elevation in low-birth-weight infants: incidence, diagnosis and management
}

\author{
Paolo Cavarzere, Marta Camilot, Florina Ion Popa, Silvana Lauriola, \\ Francesca Teofoli, Rossella Gaudino, Monica Vincenzi and Franco Antoniazzi \\ Pediatric Clinic, Department of Mother and Child, Pediatric Clinic, University Hospital of Verona, Verona, Italy
}

Correspondence should be addressed to P Cavarzere Email paolocavarzere@yahoo.it

\begin{abstract}
Objective: To evaluate the incidence of congenital hypothyroidism $(\mathrm{CH})$ with delayed TSH elevation among low-birthweight (LBW) newborns in North-Eastern Italy and to verify if they need a second or third screening.

Design: Analysis of clinical and biochemical data of newborns affected by $\mathrm{CH}$ with delayed TSH elevation identified by neonatal screening.

Methods: Data of all newborns with birth weight $(\mathrm{BW})<2500 \mathrm{~g}$ and evidence of delayed TSH elevation at newborn screening were collected between 2011 and 2014. Confirmatory tests were based on serum TSH and $\mathrm{FT}_{4}$ levels.

All their clinical signs at diagnosis were reported.

Results: $57.5 \%$ of LBW newborns with delayed TSH increase at neonatal screening presented a $\mathrm{CH}$ with delayed TSH elevation and began a treatment with L-thyroxine. The incidence of this condition in North-Eastern Italy is therefore $1: 908$. The remaining infants presented a subclinical hypothyroidism $(21.25 \%)$ or a complete normal serum thyroid function $(21.25 \%)$. These data could be drawn only from a retesting strategy of neonatal screening.

Conclusions: Our report describes the incidence of $\mathrm{CH}$ with delayed TSH rise in North-Eastern Italy and differentiates this clinical condition from other thyroid dysfunctions of preterm or LBW newborns. The second-screening strategy for $\mathrm{CH}$ in neonates with $\mathrm{BW}<2500 \mathrm{~g}$ proved useful in detecting newborns who otherwise would not be identified at the first screening.
\end{abstract}

\section{Introduction}

In preterm and low-birth-weight (LBW) infants, thyroid function is often altered. It is well known, in fact, that frequently in preterm newborns, the function of hypothalamic-pituitary-thyroid axis is attenuated at birth for an unknown postnatal duration. These babies are characterized by reduced hypothalamic TRH production, an immature response of the thyroid gland to TSH, an inefficient capacity of the thyroid follicular cells to organify iodine and a low capacity to convert $\mathrm{T}_{4}$ into active $\mathrm{T}_{3}$ (1). Intriguingly, the responses of TSH and
() 2016 European Society of Endocrinology Printed in Great Britain
$\mathrm{T}_{4}$ to TRH are normal, so the site of immaturity seems to be the hypothalamus (1). Moreover, neonatal health conditions related to preterm delivery, such as respiratory distress or drug administration, can influence serum thyroid hormone levels $(2,3,4)$. Some LBW or very-lowbirth-weight (VLBW) newborns as well as critically ill neonates often present congenital hypothyroidism $(\mathrm{CH})$ characterized by low $\mathrm{FT}_{4}$ and delayed TSH elevation $(5,6)$. The incidence of this condition is reported as 1:250 for VLBW babies and 1:1589 for LBW newborns (7). It is not 
known whether this type of $\mathrm{CH}$ is transient or permanent $(6,7,8,9,10,11)$. Likewise, it is not known if the treatment with L-thyroxine $\left(\mathrm{L}_{-} \mathrm{T}_{4}\right)$ is useful for these babies $(12,13)$. Even the diagnosis of $\mathrm{CH}$ in these newborns is not an easy task, for different reasons. First, critically ill or preterm babies hospitalized in the Neonatal Intensive Care Unit (NICU) usually have more urgent medical problems than hypothyroidism; therefore, blood samples for neonatal screening are often collected belatedly (14). Second, in preterm infants, the TSH increase usually occurs later, likely because of the above-mentioned immature function of the hypothalamic-pituitary axis $(5,15)$. As a consequence, some screening programs require a second screening test at 2 and/or 4 weeks of life for preterm newborns, babies with LBW, neonates from multiple birth and sick newborns admitted to $\operatorname{NICU}(16,17,18)$. It is still unknown whether repeating newborn screening in preterm and/or LBW infants may be useful and appropriate. In fact, while some screening programs adopt this strategy $(7,11,16,17,18,19,20)$, others think that a single determination of TSH is sufficient to identify all affected preterm babies, deeming unnecessary a systematic repetition of screening for VLBW infants, because the delayed rise in TSH is mostly considered a transient problem $(21,22)$.

The aim of this study is to identify newborns with birth weight $(\mathrm{BW})<2500 \mathrm{~g}$ affected by $\mathrm{CH}$ with delayed $\mathrm{TSH}$ elevation and, in particular, to evaluate their incidence in North-Eastern Italy. Secondly, we will determine the appropriateness of a second and/or a third test screening strategy in these neonates.

\section{Subjects and methods}

Since 1977, when the screening program for $\mathrm{CH}$ was started in North-Eastern Italy, until 2009, it used a combined approach, simultaneously determining TSH and $\mathrm{T}_{4}$ in dried blood spots taken at 3-5 days of life. Since January 2010, only the TSH has been assayed, with the repetition of the test for all newborns with BW $<2500 \mathrm{~g}$ at 15 and again at 30 days of life. According to these new procedures, today all hospitals of NorthEastern Italy collect heel prick blood samples at 36-48 $\mathrm{h}$ after birth, dry them on filter paper and send them to our laboratory in $24 \mathrm{~h}$. A solid-phase timeresolved fluoroimmunoassay method is used for TSH determination (DELFIA Neonatal hTSH Kit, Wallac, Turku, Finland). Results are available within 2 working days. The screening test is routinely repeated on the same blood spot in double every time TSH >9 U/L (threshold level for retest). When two out of three values exceed the cut-off level of $12 \mathrm{U} / \mathrm{L}$ (both for term and preterm newborns), the baby is referred to a functional thyroid assessment in serum. The cut-off is calculated at the 99th percentile of the total reference newborns' population. A second and a third filter paper samples are requested for all neonates with $\mathrm{BW}<2500 \mathrm{~g}$ at 15 and 30 days of life respectively. For these samples, a similar recalling procedure is used, setting a threshold level for retest at $4.5 \mathrm{U} / \mathrm{L}$, and the cut-off at $5 \mathrm{U} / \mathrm{L}$; the latter cut-off is determined on the basis of literature data (19).

Data of all newborns with $\mathrm{BW}<2500 \mathrm{~g}$ and evidence of $\mathrm{CH}$ with delayed TSH elevation at newborn screening were collected between 2011 and 2014. Confirmatory tests of $\mathrm{CH}$ are based on serum TSH (normal range, 0.4-6U/L) and $\mathrm{FT}_{4}$ levels (normal range, 0.7-2.3 ng/dL). TSH and $\mathrm{FT}_{4}$ were measured by a solid-phase two-site chemiluminescent immunoassay (Immunolite 2000, Siemens, Germany). Serum antibodies against thyroid peroxidase, thyroglobulin and TSH receptor were also measured. Thyroid ultrasound and scintigraphy of the thyroid gland were suggested before starting $\mathrm{L}_{-} \mathrm{T}_{4}$ treatment. Clinical signs at diagnosis were examined with particular attention to detect possible associated abnormalities. For every newborn, gestational age (GA) and BW were recorded. GA was calculated using maternal data (time elapsed from the first day of the last menstrual period to birth) associated with early prenatal ultrasound examination ( $\mathrm{GA}<20$ weeks), or with the least reliable postnatal examination. If the difference between maternal date and early dating scan was more than 7 days, the early dating scan or the postnatal examination was chosen. BW is measured by the midwife at birth. Term babies are those with GA >37 weeks.

The study was conducted in compliance with the terms of the Helsinki II Declaration. In Italy, this type of retrospective study does not require local Institutional Review Board/Institutional Ethics Committee approval.

Statistical analysis was performed using SPSS 22.0 for Windows. Normal distribution was assessed by the Kolmogorov-Smirnov test. Comparisons between groups were performed using Student's t-test or the MannWhitney $U$ test, whenever appropriate. Data are expressed as frequency, median plus range or mean \pm standard deviation (s.D.), as appropriate. Statistical significance was reached when $P$-values were less than 0.05 , and all tests were two-sided. 


\section{Results}

Between 1st January 2011 and 31st December 2014, 256491 newborns were screened for $\mathrm{CH}$. Among these, 24526 (9.6\%) had a $\mathrm{BW}<2500 \mathrm{~g}$. In particular, 20757 (8.1\%) were LBW $(1500 \mathrm{~g} \leq \mathrm{BW}<2500 \mathrm{~g}), 2811$ (1.1\%) were VLBW $(1000 \mathrm{~g} \leq \mathrm{BW}<1500 \mathrm{~g})$ and $958(0.4 \%)$ had extremely low birth weight (ELBW; BW $<1000 \mathrm{~g})$. The TSH retesting strategy on samples collected at 15 and 30 days of life from neonates with $\mathrm{BW}<2500 \mathrm{~g}$ identified 48 cases of delayed TSH rise: 11 were ELBW, 9 VLBW and the remaining $28 \mathrm{LBW}$.

One of the 48 babies was a preterm female (GA 25 weeks, BW $400 \mathrm{~g}$ ) that presented a serious necrotizing enterocolitis and died during the neonatal period. Among the remaining, 20 displayed an isolated hyperthyrotropinemia at neonatal screening and did not require therapy, while 27 presented a congenital hypothyroidism with delayed TSH elevation and began a treatment with $\mathrm{L}_{-} \mathrm{T}_{4}$. Half of the newborns who presented hyperthyrotropinemia at neonatal screening normalized their TSH level at serum evaluation and was considered 'false positive'; the latter half presented a persistent increase in TSH (>6U/L) and was considered as affected by subclinical hypothyroidism (Fig. 1).

Blood spot and serum thyroid value determinations, as well as anthropometric data of the babies of our cohort, are summarized in Table 1. Four newborns with $\mathrm{CH}$ and delayed TSH rise were term babies. $56 \%$ of treated newborns presented a BW higher than $1500 \mathrm{~g}$, while 53\% of them (30\% of the treated cohort) showed a BW higher than $2000 \mathrm{~g}$. While all patients were submitted to the first and the second blood withdrawal, only 28 newborns (12 untreated and 16 treated) were submitted to the third

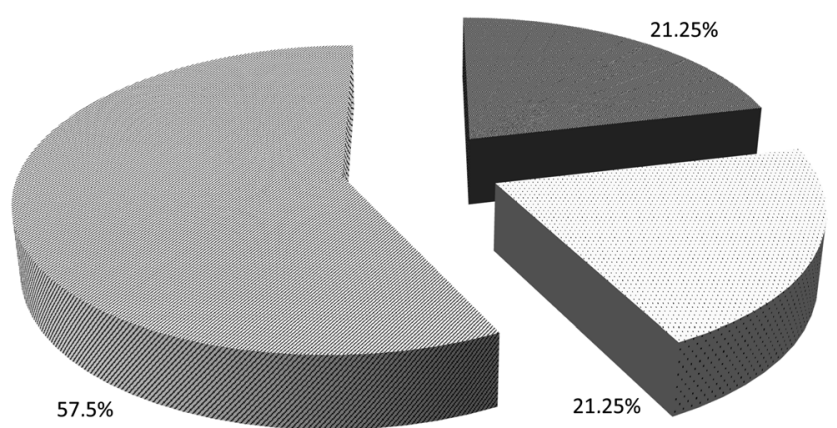

Congenital hypothyroidism with delayed TSH rise

Subclinical hypothyroidism

False-positive newborns

\section{Figure 1}

Type of thyroid dysfunction detected in LBW infants on the basis of serum data.

screening test at 30 days of life. In fact, children whose first retesting at 15 days of life had positive results, began a serum follow-up assessment of thyroid functionality, making a successive screening unnecessary.

A delayed TSH rise was evidenced at second screening in all but three infants. Similarly, three newborns with subclinical hypothyroidism were identified only at the third screening test.

Table 2 shows the incidence of $\mathrm{CH}$ with delayed TSH elevation in the North-Eastern Italy. It is also evident that at newborn screening, TSH levels are significantly lower in infants with lower BW (correlation $r=0.95$ for patients with $\mathrm{BW}<1000 \mathrm{~g})$.

It is impossible to predict how $\mathrm{CH}$ would evolve from the first test performed on blood collected between

Table 1 Determination of screening and serum thyroid values, along with anthropometric data of LBW babies of our cohort. The data are represented as numbers with frequency or median plus range.

\begin{tabular}{l}
\hline F:M \\
Gestational age (w) \\
Birth weight (g) \\
$1^{\circ}$ screening TSH (U/L) \\
$2^{\circ}$ screening TSH (U/L) \\
$3^{\circ}$ screening TSH (U/L) \\
Serum TSH (U/L) \\
Serum $\mathrm{FT}_{4}(\mathrm{ng} / \mathrm{dL})$
\end{tabular}

\begin{tabular}{c}
\hline CH with delayed TSH rise $(n=27)$ \\
\hline $12: 15$ \\
$32.0(25.0-40.0)$ \\
$1800.0(500.0-2499.0)$ \\
$5.3(0.2-11.4)$ \\
$23.9(1.2-250.0)$ \\
$44.3(8.1-395.0)^{\mathrm{a}}$ \\
$126.0(11.0-614.7)^{*, \circ}$ \\
$0.4(0.1-1.9)^{\wedge, \circ}$ \\
\hline
\end{tabular}

\begin{tabular}{c}
\hline Subclinical hypothyroidism $(n=10)$ \\
\hline $4: 6$ \\
$35.0(28.0-38.0)$ \\
$2150.0(600.0-2400.0)$ \\
$6.2(0.7-10.8)$ \\
$13.9(3.0-68.5)$ \\
$6.8(5.0-8.6)^{\S}$ \\
$11.1(6.5-35.3)^{\#}$ \\
$1.1(0.7-1.6)$ \\
\hline
\end{tabular}

\begin{tabular}{c}
\hline False-positive newborns $(n=10)$ \\
\hline $1: 9$ \\
$30.5(25.0-40.0)$ \\
$1300.0(500.0-2300.0)$ \\
$5.6(1.9-9.9)$ \\
$19.7(8.1-59.3)$ \\
$68.1(10.4-70.6)^{\mathrm{b}}$ \\
$3.8(3.4-4.0)$ \\
$1.1(0.9-1.3)$
\end{tabular}

${ }^{\S}$ Subclinical hypothyroidism vs false-positive newborns $P<0.005 ; * \mathrm{CH}$ with delayed TSH rise vs subclinical hypothyroidism $P<0.005 ;{ }^{\circ} \mathrm{CH}$ with delayed TSH rise vs false-positive newborns $P<0.05$; "Subclinical hypothyroidism vs false-positive newborns $P<0.05$; ${ }^{\wedge} \mathrm{CH}$ with delayed TSH rise vs subclinical hypothyroidism $P<0.05$.

${ }^{\text {a TSH }}$ at $2^{\circ}$ screening vs TSH at $3^{\circ}$ screening in $\mathrm{CH}$ with delayed TSH rise $P<0.01$; ${ }^{\mathrm{b}} \mathrm{TSH}$ at $2^{\circ}$ screening vs TSH at $3^{\circ}$ screening in false-positive newborns $P<0.05$. 
Table 2 Incidence of $\mathrm{CH}$ with delayed TSH elevation in relation to their BW in infants from North-Eastern Italy. Their screening and serum thyroid values are represented. The data are represented as median plus range.

\begin{tabular}{|c|c|c|c|c|c|}
\hline & \multicolumn{5}{|c|}{ Birth weight } \\
\hline & $<1000 \mathrm{~g}$ & $1000-1499$ & $1500-2499$ & $<1500$ & $<2500$ \\
\hline Total number of newborns & 958 & 2811 & 20757 & 3769 & 24526 \\
\hline $\begin{array}{l}\text { Number of newborns with } \\
\mathrm{CH} \text { with delayed TSH rise }\end{array}$ & 5 & 7 & 15 & 12 & 27 \\
\hline $\begin{array}{l}\text { Incidence of } \mathrm{CH} \text { with delayed } \\
\text { TSH rise }\end{array}$ & $1: 192$ & $1: 402$ & 1:1384 & $1: 314$ & $1: 908$ \\
\hline $1^{\circ}$ screening $\mathrm{TSH}(\mathrm{U} / \mathrm{L})$ & $1.7(0.9-2.8) *$ & $2.4(0.2-6.9)^{\S}$ & $6.8(1.0-11.4)$ & $2.1(0.2-6.9)$ & $5.3(0.2-11.4)$ \\
\hline $2^{\circ}$ screening TSH (U/L) & $11.6(8.6-182.0)$ & $14.6(1.2-250.0)$ & $35.0(3.3-65.9)$ & $14.0(1.2-250.0)$ & $23.9(1.2-250.0)$ \\
\hline $3^{\circ}$ screening TSH (U/L) & $184.5(67.6-395.0) *$ & $73.1(16.5-251.0)$ & $18.1(8.1-96.4)$ & $92.8(16.5-395.0)$ & $44.3(8.1-395.0)$ \\
\hline Serum TSH (U/L) & $150.0(42.8-183.6)$ & $120.0(35.2-614.7)$ & $99.1(11.0-258.3)$ & $149.8(35.2-614.7)$ & $126.0(11.0-614.7)$ \\
\hline Serum $\mathrm{FT}_{4}(\mathrm{ng} / \mathrm{dL})$ & $0.3(0.2-0.6)$ & $0.3(0.1-0.7)$ & $0.5(0.1-1.9)$ & $0.3(0.1-0.7)$ & $0.4(0.1-1.9)$ \\
\hline
\end{tabular}

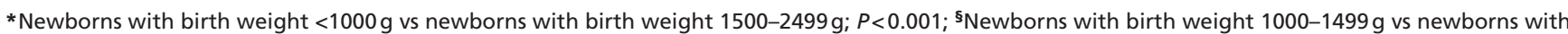
birth weight 1500-2499 g; $P<0.001$.

36- and 48-h tests. In a similar way, it is not easy to distinguish the retested babies who needed treatment from the others who did not, as shown in Fig. 2.

As expressed in Table 1 and Fig. 2, between treated infants, the concentration of serum $\mathrm{FT}_{4}$ was normal only in five cases. Of these five patients, four presented highly elevated TSH levels (>20U/L), and the remaining baby was affected by Down syndrome and his serum TSH was $15.1 \mathrm{U} / \mathrm{L}$. Among babies affected by subclinical hypothyroidism, a newborn presented a TSH of $35.3 \mathrm{U} / \mathrm{L}$ with normal $\mathrm{FT}_{4}$. In this case, TSH was repeated after a week, within the first month of life, and the values were $<10 \mathrm{U} / \mathrm{L}$, therefore a treatment was not started.

In our cohort of treated patients, we found two newborns affected by Down syndrome and seven with different types of malformations (one of them was a

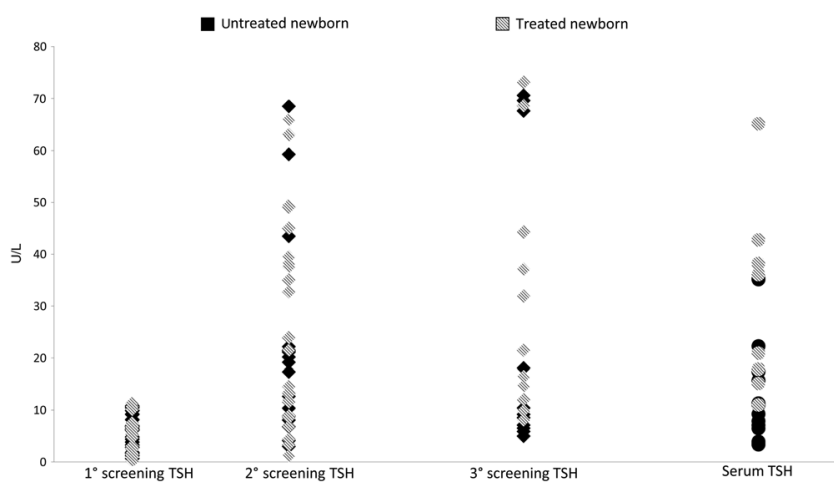

Figure 2

Screening and serum TSH values of treated and untreated LBW newborns. To improve the resolution of this figure, we used a TSH of $80 \mathrm{U} / \mathrm{L}$ as superior limit. patient with Down syndrome): two of them presented a minor malformation (bifid thumb and bilateral congenital clubfoot); the remaining five showed major malformations (of lungs, heart or kidney). 70\% of patients of this cohort presented a neonatal respiratory distress, 55\% a poor feeding and a prolonged jaundice. $25 \%$ of these babies suffered of neonatal sepsis. Moreover, $30 \%$ of these infants showed hypotonia, 25\% an anemia and $20 \%$ a hypoglycemia, but it is not clear whether these clinical signs were associated with hypothyroidism or with prematurity. Furthermore, among the treated patients, we found two couples of twins and another baby with a healthy twin. None of the babies presented thyroid maternal antibodies. 73.9\% of these newborns were submitted to thyroid ultrasonography in the neonatal period, and in all cases, thyroid gland was in the normal position - in one case, the gland was hypoplasic; in another case, it was enlarged; in the remaining newborns, it was normally sized. Only three babies were submitted to scintigraphy of the thyroid gland; in one case, the thyroid was normal, confirming the ultrasonographic result; in the remaining two babies, the gland appeared enlarged, while it appeared normal at echography. Interestingly, one of them suspended $\mathrm{L}_{-} \mathrm{T}_{4}$ treatment at the age of 3 . All of them began an $\mathrm{L}-\mathrm{T}_{4}$ treatment at $32.5 \pm 9.7$ days of life, with an average dose of $9.0 \pm 2.6 \mu \mathrm{g} / \mathrm{kg} /$ die. Although only four treated children are now older than 3 years of age, an attempt to interrupt the $\mathrm{L}-\mathrm{T}_{4}$ supplementation has already been done in nine children: six patients suspended treatment without any clinical problem; the other three continued the therapy due to the recurrence of hypothyroidism in absence of $\mathrm{L}_{-} \mathrm{T}_{4}$ supplementation (Table 3 ). 


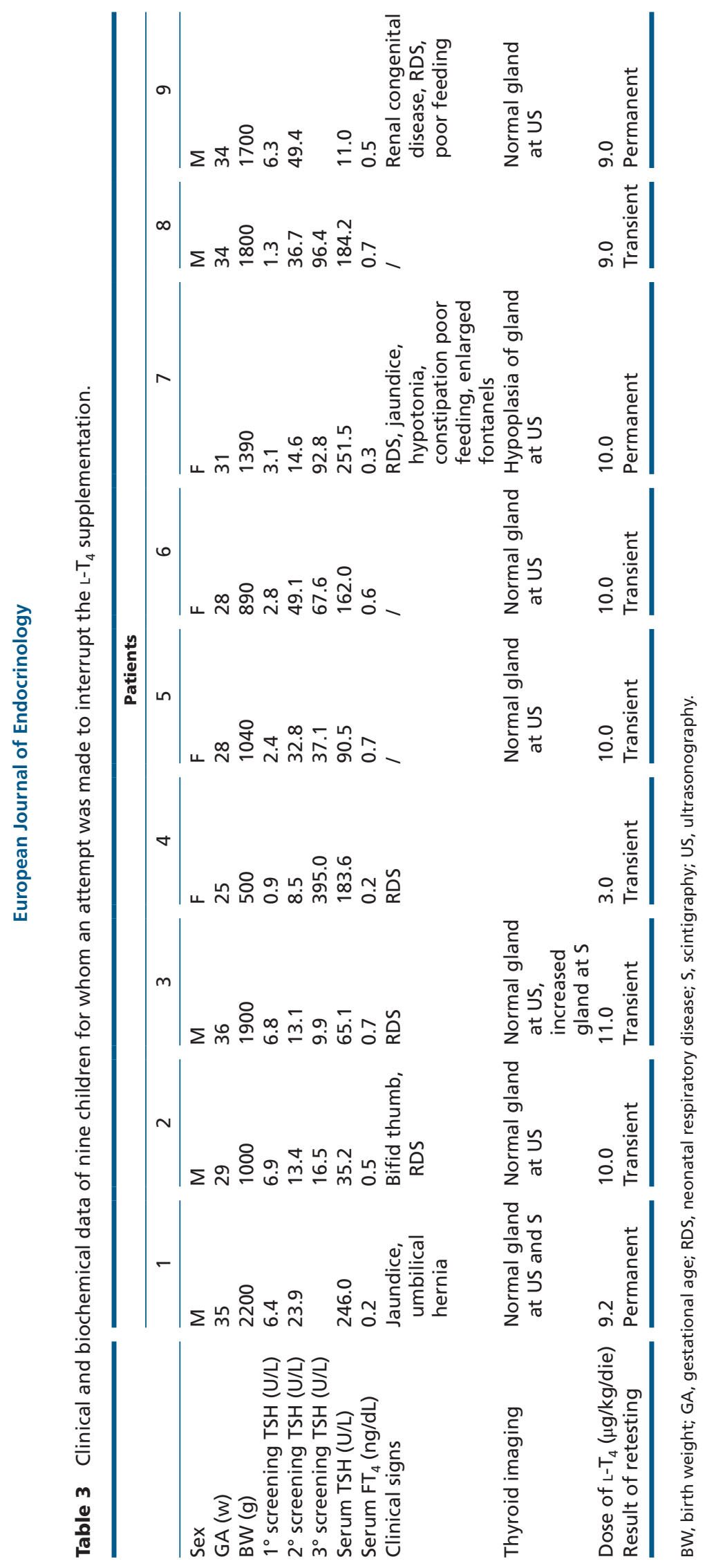

\section{Discussion}

Our report focuses on the delayed TSH rise in LBW newborns, with the aim of calculating the incidence of such a condition in a large cohort of newborns born in North-Eastern Italy between 2011 and 2014, with particular reference to the retesting protocol at 15 and 30 days of life in order to detect affected newborns, who would otherwise be missed. We found that those babies affected by $\mathrm{CH}$ with delayed TSH increase actually began a treatment with $\mathrm{L}_{\mathrm{L}} \mathrm{T}_{4}$. All of them were properly treated in accordance with the most recent recommendations of the European Society for Paediatric Endocrinology (ESPE), which suggests $\mathrm{L}^{-\mathrm{T}_{4}}$ treatment if serum TSH is persistently higher than $20 \mathrm{U} / \mathrm{L}$, even if serum $\mathrm{FT}_{4}$ is normal (17).

Untreated LBW newborns presented normal serum $\mathrm{FT}_{4}$ levels: $50 \%$ of them showed normal serum TSH level; the remaining 50\% presented a transitory alteration of TSH level (TSH between 6 and 20U/L), which was either normalized during the first weeks of life or persisted as subclinical hypothyroidism with $\mathrm{FT}_{4}$ always in the reference range for age. Some of these babies were preterm neonates with an immaturity of the hypothalamus-pituitary-thyroid axis (1). In other babies, alteration of thyroid function might also be due to drug treatments (as dopamine, dobutamine, caffeine, morphine and glucocorticoids) $(13,23,24)$, or either to a severe nonthyroidal illness $(3,4,24,25,26)$, or finally to insufficient or excessive iodine intake $(27,28)$. Lastly, in babies presenting subclinical hypothyroidism, a dyshormonogenesis defect cannot be excluded $(29,30)$. Anyhow, children with subclinical hypothyroidism should be subject to periodic follow-up during childhood, because it may evolve into a mild hypothyroidism (31).

Although $\mathrm{CH}$ with delayed TSH rise and subclinical hypothyroidism in children with low BW might be due to similar causes, borderline conditions may always occur, and most patients with $\mathrm{CH}$ and delayed TSH increase need treatment only for a short period of time. Nevertheless, a distinction between these two conditions is fundamental; in fact, before these babies started treatment, their TSH and $\mathrm{FT}_{4}$ serum levels were significantly different from those of other groups of newborns (Table 1).

Notably, $56 \%$ of patients with delayed TSH rise presented $\mathrm{BW}>1500 \mathrm{~g}$ and four of them are term babies. Therefore, it is evident that $\mathrm{CH}$ with delayed TSH rise occurs not only in preterm babies, but also 
in all newborn population, as other authors have also attested $(7,9,12)$.

Some issues still remain unanswered: which is the true incidence of the $\mathrm{CH}$ with delayed TSH rise? Is it really useful to start a treatment in this clinical condition? Which is the most appropriate diagnostic strategy in order to identify $\mathrm{CH}$ with delayed TSH rise: retesting at 15 and then at 30 days of life, or the collection of just one of these two retestings is sufficient?

Before answering the first question, it is worth noting that if we had contemplated in our analysis the 20 untreated newborns presenting at screening test with a hyperthyrotropinemia, our incidence would have been considerably higher (1:96 for ELBW, 1:312 for VLBW and 1:741 for LBW). Nevertheless, the incidence of $\mathrm{CH}$ with delayed TSH rise in our cohort of North-Eastern Italy is almost comparable with the data reported by Larson and coworkers regarding a larger number of newborns identified in Massachusetts (7). It appears to be lower than the incidence reported by Chul Woo about the Rhode Island experience on a smaller number of infants (8) and by Bijarnia on the Australian experience of a large cohort of newborns (16). In Italy, the incidence of $\mathrm{CH}$ with delayed TSH rise reported by Corbetta and coworkers (19) is similar to ours.

The second question about the usefulness of an $\mathrm{FT}_{4}$ supplementation in these babies remains unanswered. In fact, the appropriateness of a treatment in case of mild elevation of serum TSH level is still a matter of discussion, although there is some evidence that most cases present transient hypothyroidism $(6,7,8,32)$. Nevertheless, some authors suggest that it is prudent to treat this hypothyroidism until it is resolved $(12,33)$. The most recent ESPE guidelines suggest a treatment if the serum TSH is persistently $>20 \mathrm{U} / \mathrm{L}$ even if serum thyroid hormones are normal. Clearly, it is necessary to avoid overtreatment and to retest thyroid function after 3 years of life, especially if the gland is normally located (17). The data presented in Table 3, describing those children for whom an attempt was made to interrupt the $\mathrm{L}_{-} \mathrm{T}_{4}$ supplementation, confirm that they needed treatment, because their thyroid dysfunction, even if transient, was severe at birth.

A limitation of our study is the follow-up, which was managed by different physicians for different newborns. As a consequence, some discrepancies may be observed in the dose of treatment suggested at the beginning of the therapy, and in the indications given about the suitability of starting or withdrawing it. Nevertheless, all treated patients fulfilled requirements outlined in the most recent
ESPE guidelines on the start of treatment; the same can be said about its cessation (17); for that reason, we deemed these differences of secondary importance in relation to the purpose of this paper.

At present, an attempt to suspend the $\mathrm{L}_{-} \mathrm{T}_{4}$ supplementation has been made only in nine children; three of them are continuing the therapy. These permanent cases confirm that $\mathrm{CH}$ with delayed rise is not a marginal problem and needs to be promptly recognized and treated. Serum TSH does not predict permanent or transient hypothyroidism. Notably, three of our patients presented a serum TSH higher than $160 \mathrm{U} / \mathrm{L}$ and interrupted the treatment before 2 years of life. All of them were preterm babies and their thyroid gland was likely incapable to cope with external stimuli, such as iodine overload or drugs.

Similarly, TSH value at screening does not distinguish babies who will need treatment from those who will not (Fig. 2). TSH levels are very low in ELBW and VLBW infants at first screening, and these values clearly increase at 15 days of life and, even more significantly, at 1 month of life, likely because of an immaturity of hypothalamic-pituitary-thyroid axis. Consequently, TSH levels determined in the first days in newborns with low BW are not sufficient to detect $\mathrm{CH}$. This result confirms previous data and is in line with more recent guidelines on screening, diagnosis and management of $\mathrm{CH}(7,11$, $16,17,18,19,20)$. On the contrary, some authors affirm that the repetition of tests for $\mathrm{CH}$ in preterm babies or VLBW is unnecessary $(21,22)$. In their view, it is more consistent to use a low TSH screening threshold in order to avoid retesting (21). However, the reduction in the TSH threshold may lead to a greatly increased recall rate at screening, and not least, there may be the risk of missing patients. Based on our results, it appears clear that a second screening test at 15 days of life is necessary in high-risk newborns for identifying delayed TSH increase, whereas the execution of a third screening test for newborns with a low BW remains a matter of debate. Further and more specific studies, sustained by an appropriate analysis of cost-benefit ratio, are required. In our study, the 2nd screening detected all affected patients, except three patients with malformations or Down syndrome, which is per se associated with thyroid dysfunction (34). It is necessary to start a clinical follow-up of LBW neonates, especially in case they have clinical malformations, and to control their thyroid function, if there are clinical grounds for suspecting abnormalities. In a newborn with a suspect hypothyroidism, waiting for a 3rd screening test at 1 month of age before starting a 
treatment may compromise the patient's neurocognitive development. Impaired intellectual development is also described in transient neonatal hypothyroidism and hyperthyrotropinemia $(35,36)$. More recent literature suggests that $\mathrm{L}^{-} \mathrm{T}_{4}$ therapy has to be started as soon as possible, preferably within 2 weeks of life $(17,18)$.

In conclusion, our report describes the incidence of $\mathrm{CH}$ with delayed TSH rise in a large cohort of newborns born in North-Eastern Italy between 2011 and 2014 and differentiates this clinical condition from other typical thyroid alterations in preterm newborns. Although this type of $\mathrm{CH}$ is usually more common in severe preterm infants, a large number of affected babies were term babies with a $\mathrm{BW}$ higher than $2000 \mathrm{~g}$. In neonates with $\mathrm{BW}<2500 \mathrm{~g}$, a second screening test performed at 15 days of life for $\mathrm{CH}$ proved essential in detecting newborns who would not otherwise be identified. On the basis of our experience, the 2 nd retesting at 30 days of life seems dispensable, although further and more specific studies, sustained by an appropriate analysis of cost-benefit ratio, are required.

\section{Declaration of interest}

The authors declare that there is no conflict of interest that could be perceived as prejudicing the impartiality of the research reported.

\section{Funding}

This research did not receive any specific grant from any funding agency in the public, commercial or not-for-profit sector.

\section{Author contribution statement}

All the authors had full access to all of the data in the study and take responsibility for the integrity of the data and the accuracy of the data analysis. Moreover, all authors read and approved the final manuscript. Conceived the study: P C, M C, F T; Acquisition of data: F I P, S L; Analysis and interpretation of data: $\mathrm{P} C, \mathrm{M} \mathrm{V}$; Drafting the manuscript: $\mathrm{P} C, \mathrm{M} \mathrm{V}$; Critical revision of the manuscript: $M C, F A, R$ G; Coordination of study: M C, F A.

\section{References}

1 Ogilvy-Stuart AL. Neonatal thyroid disorders. Archives of Disease in Childhood. Fetal and Neonatal Edition 200287 165-171. (doi:10.1136/ fn.87.3.F165)

2 Murphy N, Hume R, van Toor H, Matthews TG, Ogston SA, Wu SY, Visser TJ \& Williams FL. The hypothalamic-pituitary-thyroid axis in preterm infants; changes in the first 24 hours of postnatal life. Journal of Clinical Endocrinology and Metabolism 200489 2824-2831. (doi:10.1210/jc.2003-030317)

3 Redding RA \& Pereira C. Thyroid function in respiratory distress syndrome (RDS) of the newborn. Pediatrics 197454 423-428.

4 Franklin RC, Purdie GL \& O'Grady CM. Neonatal thyroid function: prematurity, prenatal steroids, and respiratory distress syndrome. Archives of Disease in Childhood 198661 589-592. (doi:10.1136/ adc.61.6.589)
5 American Academy of Pediatrics, Rose SR, American Thyroid Association Section on Endocrinology and Committee on Genetics, Brown RS, Lawson Wilkins Pediatric Endocrine Society Public Health Committee, Foley T, Kaplowitz PB, Kaye CI, Sundararajan S \& Varma SK. Update of newborn screening and therapy for congenital hypothyroidism. Pediatrics 2006117 2290-2303. (doi:10.1542/ peds.2006-0915)

6 Mandel SJ, Hermos RJ, Larson CA, Prigozhin AB, Rojas DA \& Mitchell ML. Atypical hypothyroidism and the very low birthweight infant. Thyroid 2000 10 693-695. (doi:10.1089/10507250050137770)

7 Larson C, Hermos R, Delaney A, Daley D \& Mitchell M. Risk factors associated with delayed thyrotropin elevations in congenital hypothyroidism. Journal of Pediatrics 2003143 587-591. (doi:10.1067/ S0022-3476(03)00332-9)

8 Woo HC, Lizarda A, Tucker R, Mitchell ML, Vohr B, Oh W \& Phornphutkul C. Congenital hypothyroidism with a delayed thyroidstimulating hormone elevation in very premature infants: incidence and growth and developmental outcomes. Journal of Pediatrics 2011 158 538-542. (doi:10.1016/j.jpeds.2010.10.018)

9 Srinivasan R, Harigopal S, Turner S \& Cheetham T. Permanent and transient congenital hypothyroidism in preterm infants. Acta Paediatrica 2012101 e179-e182 (doi:10.1111/j.16512227.2011.02536.x)

10 Mengreli C, Kanaka-Gantenbein C, Girginoudis P, Magiakou MA, Christakopoulou I, Giannoulia-Karantana A, Chrousos GP \& Dacou-Voutetakis C. Screening for congenital hypothyroidism: the significance of threshold limit in false-negative results. Journal of Clinical Endocrinology and Metabolism 201095 4283-4290. (doi:10.1210/jc.2010-0057)

11 Vigone MC, Caiulo S, Di Frenna M, Ghirardello S, Corbetta C, Mosca F \& Weber G. Evolution of thyroid function in preterm infants detected by screening for congenital hypothyroidism. Journal of Pediatrics 2014164 1296-1302. (doi:10.1016/j.jpeds.2013.12.048)

12 Lafranchi SH. Congenital hypothyroidism: delayed detection after birth and monitoring treatment in the first year of life. Journal of Pediatrics 2011158 525-527. (doi:10.1016/j.jpeds.2010.11.030)

13 Deladoëy J, Ruel J, Giguère Y \& Van Vliet G. Is the incidence of congenital hypothyroidism really increasing? A 20-year retrospective population-based study in Québec. Journal of Clinical Endocrinology and Metabolism 201196 2422-2429. (doi:10.1210/jc.2011-1073)

14 Cavarzere P \& Tatò L. Disorders of thyroid function. In Springer Volume Neonatology A Practical Approach to Neonatal Diseases, edn 1, ch 122, pp 989-999. Eds G Buonocore, R Bracci \& M Weindling. New York, NY, USA: Springer, 2011.

15 Grüters A \& Krude H. Update on the management of congenital hypothyroidism. Hormone Research 200768 107-111. (doi:10.1159/000110591)

16 Bijarnia S, Wilcken B \& Wiley VC. Newborn screening for congenital hypothyroidism in very-low-birth-weight babies: the need for a second test. Journal of Inherited Metabolic Disease 201134 827-833. (doi:10.1007/s10545-011-9286-8)

17 Léger J, Olivieri A, Donaldson M, Torresani T, Krude H, van Vliet G, Polak M, Butler G, ESPE-PES-SLEP-JSPE-APEG-APPES-ISPAE \& Congenital Hypothyroidism Consensus Conference Group. European Society for Paediatric Endocrinology consensus guidelines on screening, diagnosis, and management of congenital hypothyroidism. Journal of Clinical Endocrinology and Metabolism 201499 363-384. (doi:10.1210/jc.2013-1891)

18 Cassio A, Corbetta C, Antonozzi I, Calaciura F, Caruso U, Cesaretti G, Gastaldi R, Medda E, Mosca F, Pasquini E et al. The Italian screening program for primary congenital hypothyroidism: actions to improve screening, diagnosis, follow-up, and surveillance. Journal of Endocrinological Investigation 201336 195-203. (doi:10.3275/8849)

19 Corbetta C, Weber G, Cortinovis F, Calebiro D, Passoni A, Vigone MC, Beck-Peccoz P, Chiumello G \& Persani L. A 7-year experience with low blood TSH cutoff levels for neonatal screening reveals an unsuspected 
frequency of congenital hypothyroidism (CH). Clinical Endocrinology 200971 739-745. (doi:10.1111/j.1365-2265.2009.03568.x)

20 Gruñeiro-Papendieck L, Chiesa A, Mendez V, Santilli A \& Prieto L. Efficacy of congenital hypothyroidism neonatal screening in preterms less than 32 weeks of gestational age: more evidence. Journal of Pediatric Endocrinology and Metabolism 200518 373-377.

21 Korada M, Pearce MS, Ward Platt MP, Avis E, Turner S, Wastell H \& Cheetham T. Repeat testing for congenital hypothyroidism in preterm infants is unnecessary with an appropriate thyroid stimulating hormone threshold. Archives of Disease in Childhood. Fetal and Neonatal Edition 200893 F286-F288. (doi:10.1136/ adc.2007.134999)

22 Vincent MA, Rodd C, Dussault JH \& Van Vliet G. Very low birth weight newborns do not need repeat screening for congenital hypothyroidism. Journal of Pediatrics 2002140 311-314. (doi:10.1067/ mpd.2002.120268)

23 Van den Berghe G, de Zegher F \& Lauwers P. Dopamine suppresses pituitary function in infants and children. Critical Care Medicine 1994 22 1747-1753. (doi:10.1097/00003246-199422110-00008)

24 Williams FL, Ogston SA, van Toor H, Visser TJ \& Hume R. Serum thyroid hormones in preterm infants: associations with postnatal illnesses and drug usage. Journal of Clinical Endocrinology and Metabolism 200590 5954-5963. (doi:10.1210/jc.2005-1049)

25 Simpson J, Williams FL, Delahunty C, van Toor H, Wu SY, Ogston SA Visser TJ, Hume R \& Scottish Preterm Thyroid Group. Serum thyroid hormones in preterm infants and relationships to indices of severity of intercurrent illness. Journal of Clinical Endocrinology and Metabolism 200590 1271-1279. (doi:10.1210/jc.2004-2091)

26 Goldsmit GS, Valdes M, Herzovich V, Rodriguez S, Chaler E, Golombek SG \& Iorcansky S. Evaluation and clinical application of changes in thyroid hormone and TSH levels in critically ill full-term newborns. Journal of Perinatal Medicine 201139 59-64. (doi:10.1515/ jpm.2010.120)

27 Belfort MB, Pearce EN, Braverman LE, He X \& Brown RS. Low iodine content in the diets of hospitalized preterm infants. Journal of Clinical
Endocrinology and Metabolism 201297 E632-E636. (doi:10.1210/ jc.2011-3369)

28 l'Allemand D, Grüters A, Heidemann P \& Schürnbrand P. Iodineinduced alterations of thyroid function in newborn infants after prenatal and perinatal exposure to povidone iodine. Journal of Pediatrics 1983102 935-938.

29 Grüters A, Finke R, Krude H \& Meinhold H. Etiological grouping of congenital hypothyroidism with a thyroid gland in situ. Hormone Research 199441 3-9.

30 De Vijlder JJ, Ris-Stalpers C \& Vulsma T. Inborn errors of thyroid hormone biosynthesis. Experimental and Clinical Endocrinology \& Diabetes 1997105 32-37.

31 Calaciura F, Motta RM, Miscio G, Fichera G, Leonardi D, Carta A, Trischitta V, Tassi V, Sava L \& Vigneri R. Subclinical hypothyroidism in early childhood: a frequent outcome of transient neonatal hyperthyrotropinemia. Journal of Clinical Endocrinology and Metabolism 200287 3209-3214 (doi:10.1210/jcem.87.7.8662)

32 Krude $\mathrm{H} \&$ Blankenstein O. Treating patients not numbers: the benefit and burden of lowering TSH newborn screening cut-offs. Archives of Disease in Childhood 201196 121-122 (doi:10.1136/adc.2009.174466)

33 LaFranchi SH. Increasing incidence of congenital hypothyroidism: some answers, more questions. Journal of Clinical Endocrinology and Metabolism 201196 2395-2397 (doi:10.1210/jc.2011-1850)

34 van Trotsenburg AS, Kempers MJ, Endert E, Tijssen JG, de Vijlder JJ \& Vulsma T. Trisomy 21 causes persistent congenital hypothyroidism presumably of thyroidal origin. Thyroid $2006 \mathbf{1 6} 671-680$. (doi:10.1089/thy.2006.16.671)

35 Azizi F, Afkhami M, Sarshar A \& Nafarabadi M. Effects of transient neonatal hyperthyrotropinemia on intellectual quotient and psychomotor performance. International Journal for Vitamin and Nutrition Research 200171 70-73. (doi:10.1024/0300-9831.71.1.70)

36 Calaciura F, Mendorla G, Distefano M, Castorina S, Fazio T, Motta RM, Sava L, Delange F \& Vigneri R. Childhood IQ measurements in infants with transient congenital hypothyroidism. Clinical Endocrinology 1995 43 473-477. (doi:10.1111/j.1365-2265.1995.tb02620.x)

Received 19 December 2015

Revised version received 29 June 2016

Accepted 10 August 2016 